\title{
Probable protective role of diabetes mellitus in takotsubo cardiomyopathy: a review
}

\author{
Shreyas Gowdar', Samridhi Syal ${ }^{2}$, Lovely Chhabra ${ }^{2,3}$ \\ ${ }^{1}$ Department of Medicine, Baystate Medical Center, Springfield, MA 01199, USA. \\ ${ }^{2}$ Department of Cardiovascular Diseases, Heartland Regional Medical Center, Marion, IL 62959, USA. \\ ${ }^{3}$ SIU School of Medicine, Southern Illinois University, Carbondale, IL 62901, USA.
}

Correspondence to: Dr. Lovely Chhabra, Department of Cardiovascular Diseases, Heartland Regional Medical Center, 3331 W. Deyoung Street, Marion, IL 62959, USA. E-mail: lovids@hotmail.com

How to cite this article: Gowdar S, Syal S, Chhabra L. Probable protective role of diabetes mellitus in takotsubo cardiomyopathy: a review. Vessel Plus 2017;1:129-36.

\begin{abstract}
Article history:
Received: 18 Apr 2017

Accepted: 24 Jul 2017

Published: 26 Sep 2017
\end{abstract}

\section{Key words:}

Diabetes mellitus,

stress cardiomyopathy,

takotsubo cardiomyopathy

\begin{abstract}
Takotsubo cardiomyopathy (TC) is a syndrome that predominantly affects postmenopausal women and is characterized by transient regional systolic dysfunction of the left ventricle which occurs in the absence of angiographic evidence of significant obstructive coronary artery disease. It is often but not always triggered by emotional or physical stressful stimuli. In most cases, the regional ventricular dysfunction extends beyond a single epicardial coronary artery territory. It typically involves the apex, with rare atypical presentations involving the base and right ventricle. Although the pathophysiological underpinnings of TC have not been completely elucidated, possible mechanisms include catecholamine overactivity, diffuse multivessel coronary spasm, microvascular dysfunction and estrogen deficiency. The prevalence of diabetes mellitus has been noted to be low in multiple studies of patients with TC. In this review, the authors discuss the association between diabetes mellitus and TC, with a special emphasis on the possible protective effect of diabetes mellitus in development of TC.
\end{abstract}

\section{INTRODUCTION}

Takotsubo cardiomyopathy (TC), also known as apical ballooning syndrome or broken heart syndrome, is a syndrome characterized by transient regional systolic dysfunction of the left ventricle that occurs in the absence of angiographic evidence of significant obstructive coronary artery disease (CAD).$^{[1,2]}$ It is usually but not always triggered by emotional or physical stressful stimuli. It is predominantly seen in postmenopausal women. The syndrome may acutely mimic as an acute coronary syndrome; however the regional left ventricular dysfunction extends often beyond a single epicardial coronary artery territory. The first case was reported by Sato in Japan in 1990, ${ }^{[3]}$ and since then, this syndrome has been increasingly recognized around the globe. The typical and most common presentation consists of apical dysfunction leading to apical ballooning appearance on coronary angiography, with basal hypercontractility. Atypical variants/presentations of TC are rare, and include transient dysfunction of basal, mid ventricular or right ventricular myocardium, with apical sparing. Although the pathophysiological underpinnings of TC have not been completely elucidated, possible mechanisms include catecholamine over-activity causing myocardial

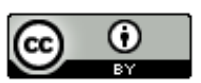

This is an open access article licensed under the terms of Creative Commons Attribution 4.0 International License (https://creativecommons.org/licenses/by/4.0/), which permits unrestricted use, distribution, and reproduction in any medium, as long as the original author is credited and the new creations are licensed under the identical terms.

For reprints contact: service@oaepublish.com

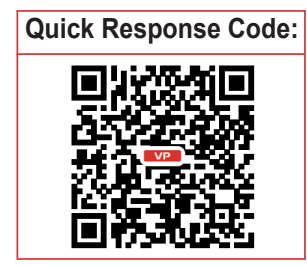


stunning, diffuse multi-vessel coronary spasm, microvascular dysfunction and estrogen deficiency. ${ }^{[4]}$

An increased catecholamine surge leading to exaggerated cardiac sympathetic stimulation has long been thought to be a plausible mechanism of TC pathogenesis. Animal studies using rat models have provided further evidence that left ventricular apical or midventricular dysfunction in TC patients could be a result of catecholamine mediated effects on cardiac beta receptors, particularly the pleiotropic $\beta 2$ receptors. This is related to epinephrine and isoprenaline mediated switching of beta receptor activation from cardiostimulation to cardioinhibitory pathways, via the activation of $\mathrm{Gi}$ proteins, instead of $\mathrm{Gs}$ proteins. ${ }^{[5]}$ Exaggerated sympathetic stimulation has been inferred from markedly elevated plasma catecholamine levels, both epinephrine and norepinephrine, in TC patients. ${ }^{[5]}$ The specific mechanism of catecholamine mediated myocardial stunning is unclear, with possible mechanisms being decreased myocardial blood flow or direct catecholamine myocardial toxicity. Coronary microvascular dysfunction leading to impaired microcirculatory perfusion and myocardial stunning has also been thought to play a significant role in the development of TC. ${ }^{[4,6,7]}$ Human and animal studies have illustrated the primary role of autonomic nerves innervating the heart and a secondary role of the adrenal medulla with sympathetic and parasympathetic influences on neurovisceral myocardial injury. ${ }^{[5]}$ Neural disconnection between the brain and the heart in brain death and cardiac transplantation have been shown to blunt neuromyocardial damage and cause an amelioration of electrocardiographic abnormalities. ${ }^{[5]}$ Similarly, diabetes mellitus (DM) is associated with autonomic neuropathy and thus may exert an independent potential influence on the pathogenesis of TC. ${ }^{[1]}$ This article aims to review the association between DM and TC, based on the knowledge gained from the recent studies.

\section{DATA}

We searched PubMed/Medline, Scopus and Google Scholar for original articles published between 1990 and 2016, focusing on TC and DM. ${ }^{[1]}$ The keywords used to conduct the relevant literature search, alone and/or in combination, were "takotsubo cardiomyopathy", "stress cardiomyopathy", "apical ballooning syndrome", "diabetes", "diabetes mellitus", "prevalence", "incidence" and "association". All articles published in the English language were then independently reviewed. Papers included were original research, review, case reports and relevant correspondences. After a comprehensive review of the articles selected, we used literature relevant to our current discussion.

\section{Retrospective studies}

A large international collaborative systematic review sought to evaluate the prevalence of comorbidities, cardiovascular and others, in TC patients. ${ }^{[8]}$ The authors evaluated 19 large case series between 2007 and 2013 which included 1,109 patients with TC. Among the 1,109 patients with TC (86\% females), hypertension was present in $54 \%$ (range $27-83 \%$ ), dyslipidemia in $32 \%$ (range $7-59 \%$ ), but DM in only $17 \%$ (prevalence ranging between 4-34\%). Of all the 19 studies, 11 demonstrated DM prevalence to be < 14\%, with 6 studies demonstrating a prevalence rate of $\mathrm{DM}<10 \%$. Although there was no control group for comparison of the TC patients to the general population, or to the population of acute myocardial infarction (MI) patients, the authors concluded that traditional cardiovascular risk factors are commonly prevalent in TC patients, with frequencies similar to those seen in acute MI patients. ${ }^{\left[{ }^{8]}\right.}$ However, the prevalence of DM in this study appeared to correlate with the rates demonstrated by a large metanalysis, ${ }^{[5]}$ which led to support the hypothesis of DM being a protective factor in TC patients.

A Spanish study comprising 328 TC patients compared the "primary" (265 patients) and "secondary" (63 patients) forms of TC. ${ }^{\left[{ }^{9]}\right.}$ Primary TC was described as that triggered by a psychic stress or without stressful stimulus. Additionally, secondary TC was described as the one triggered by the presence of physical stressors such as sepsis, intracranial hemorrhage or cerebrovascular accident, severe trauma, bronchospasm, surgery or other critical illnesses. Patients with secondary TC forms demonstrated more hospital complications, higher major adverse cardiac events, higher mortality and higher rates of recurrence. The prevalence of hypertension was $68.3 \%$ in the primary TC cohort and $60.3 \%$ in the secondary TC cohort. Dyslipidemia was seen in $44.9 \%$ and $41.2 \%$ in the primary and secondary forms of TC respectively. The prevalence of DM was overall low (13.1\%), and the prevalence in the primary and secondary forms of TC, was $12.8 \%$ and $14.2 \%$, respectively. Hypertension was slightly more and DM was slightly less prevalent in the "primary" TC group compared to the "secondary" TC group. ${ }^{[9,10]}$ Thus, this study further underscores the low rates of DM in TC patients.

In another small retrospective study, the role of coronary microvascular function in patients with TC was compared with controls without CAD, using invasive angiography and TIMI frame counts. ${ }^{[11]}$ The prevalence of DM was low (only $6.25 \%$ ), again suggesting that the presence of DM may confer a protective effect in the 
development of TC.

In this retrospective study based on the National Inpatient Samples (NIS) Database 2008 to 2009, a total of 24,701 patients with takotsubo cardiomyopathy were identified (mean age was $66.9 \pm 30.7$ years with patients aged > 64 years comprising $59.6 \%$ of the group). ${ }^{[12]}$ Among the patients with TC, $89 \%$ were females and $11 \%$ males. Although the primary outcome of the study was in-patient mortality but other associated chronic comorbidities were also reported. The prevalence of hypertension and hyperlipidemia was found to be $58.4 \%$ and $37.5 \%$ respectively. And the prevalence of diabetes mellitus was $18.9 \%$, which was lower than the prevalence of diabetes in the general population group aged $\geq 65$ years $(25.9 \%$ in general population aged $>65$ years, National Diabetes Statistics Report 2014).

In a retrospective study and analysis of the electronic medical records of patients diagnosed with apical ballooning syndrome or stress cardiomyopathy at Mayo Clinic, a total of 224 patients were included (94.6\% were females and mean age $71.7 \pm 10.4$ years). ${ }^{[13]}$ Hypertension was present in $70.9 \%$ of the patients while diabetes was present in only a small percentage of the patients (13.8\%). Again, this study supports the protective role of diabetes in $\mathrm{TC}$.

In a different retrospective descriptive study reviewing patients with the discharge diagnosis of TC between 2003 and 2014 at Einstein Medical Center in Philadelphia, a total of 206 TC patients were identified. ${ }^{[14]}$ Overall mean age was 67.8 years. Out of the 206 patients, 179 (87\%) were females and 41 (19\%) had diabetes. As compared to the low prevalence of diabetes in these patients, the prevalence of hypertension was seen to be much higher $(68.4 \%)$.

In a retrospective study of 5,484 patients referred to the coronary care unit for acute coronary syndrome (ACS) between 2001 and 2013, the clinical records were studied and reviewed. ${ }^{[15]}$ Out of this, 90 patients were found to have TC. The mean age of patients with TC was $71.9 \pm 12.7$ years and $97 \%$ were females. While the prevalence of hypertension was comparable in both groups (46\% and $47 \%$ in TC and ACS group), DM was present in only $9 \%$ of TC patients as compared to $17 \%$ of patients with ACS. A lower prevalence of DM in $\mathrm{TC}$ again signifies its protective effect in the disease.

In another study utilizing the NIS Database data 2007 to 2012 , Khera et al. ${ }^{[16]}$ identified 22,005 patients who were discharged with a primary diagnosis of TC in the US. The number of hospitalizations was seen to have increased nearly 3-fold, from 1,642 cases in 2007 to 5,480 cases in 2012 . The mean age of patients with TC was 65.7 years and more than 9 out of $10(92.0 \%)$ were women. Whereas hypertension was present in $64.2 \%$ patients (ranging 59.2-67.6\%), uncomplicated DM was seen in only $18 \%$ of the patients (ranging 15.6-19.3\%). On the other hand, complicated DM was found to be present in even a lower percentage of TC patients (only $2.6 \%$, ranging $1.4-3.2 \%$ ). This study strongly supports the role of diabetic autonomic neuropathy/end-organ damage protecting the heart from catecholamine damage in TC.

\section{Prospective studies}

In a multi-center study conducted prospectively in Europe and North America between January 2005 and October 2010, 256 patients with TC were included and assessed at initial presentation as well as 1-6 months after the acute event (mean age 69 years and $89 \%$ females). ${ }^{[17]}$ Whereas hypertension was noted in $73 \%$ of the patients, DM was noted in only $19 \%$ of the patients. This data also depicts a low prevalence of DM in TC.

Another prospective study comprising 100 patients (between 2002-2010) was conducted to determine the incidence of TC and associated risk factors for the development of heart failure in TC. ${ }^{[18]}$ The mean age was 68 years and $89 \%$ were post-menopausal women. While hypertension was present in $68 \%$ of the patients with TC, DM was present in only $18 \%$ of the patients. As seen in other studies, this study also suggests a protective role of DM in TC.

\section{Registries}

In a large multicenter prospective registry (RETAKO registry, Spain), 202 patients with TC were studied (90\% females, mean age 70 years). ${ }^{[19]}$ The incidence of DM was $15 \%$ while the prevalence of other standard cardiac risk factors including hypertension and dyslipidemia were $69 \%$ and $41 \%$ respectively. This study again suggested a relative low prevalence of DM in TC.

A more recent study utilizing the data from the International Takotsubo registry compared 455 patients with TC to age and gender matched patients with ACS (mean age $67.7 \pm 12.5$ years and $68.7 \pm 12.3$ years, respectively and $90.3 \%$ women in both cohorts). ${ }^{[20]} \mathrm{DM}$ prevalence was $12.8 \%$ in the TC group, and $26.6 \%$ in the ACS cohort. Prevalence of hypertension was comparable among both the cohorts (about 65\% in each cohort). ${ }^{[20,21]}$ Thus, this study further strengthens the hypothesis of DM being possibly protective against the development of TC. 
In this partial retrospective and partial prospective study, 190 patients enrolled in the Takotsubo Italian Network Registry were selected (mean age $66.0 \pm 11.4$ years). ${ }^{[22]}$ Out of these 190 patients, 175 were female (92\%). As compared to the prevalence of hypertension, which was found to be $48.4 \%$, the prevalence of diabetes was found to be very low $(5.7 \%)$. Thus, this study also favors the notion of DM playing a protective role in TC.

\section{Case control studies}

In a case-control study utilizing the NIS 2008-2009, Falola et al. ${ }^{[23]}$ identified 1,724 patients with TC (average age 65.3 years) as cases. When cases were compared with controls [patients admitted with ST-Elevation myocardial infarction (STEMI) for initial care], it was seen that females comprised $90.2 \%$ of the patients in the TC group vs. only $35.7 \%$ in the STEMI (control) group. The prevalence of hypertension was noted to be $58.6 \%$ and $66 \%$ among the cases and control groups respectively. On the other hand, diabetes was considered as a protective factor for TC as the prevalence of diabetes in TC cases was quite low (1.6\%). DM prevalence was significantly lower in TC patients when compared to those with STEMI (odds ratio $0.3, P<0.0001){ }^{[23]}$

In another case control study, a total of 505 TC patients were identified from the Swedish Angiography and Angioplasty Registry between 2009 and 2013 using the Mayo Clinic criteria. ${ }^{[24]}$ The TC patients were matched for age and gender with controls with and without CAD. All the patients presented with an acute event/chest pain and underwent coronary angiography to identify the underlying cause. Among the 505 patients with TC, $442(87.5 \%)$ were women with a mean age of 67 \pm 10 years. Only 33 patients with TC $(6.5 \%)$ had DM as compared to 200 patients (19.8\%) with CAD, which further supports that DM plays a protective role in TC.

In another Polish case-control study, 101 patients hospitalized with TC were studied. ${ }^{[25]}$ The control group consisted of 101 female patients diagnosed with anterior myocardial infarction with STEMI. The mean age was $67.6 \pm 14.2$ years in the TC group vs. $72.1 \pm 13.1$ years in the control group. Females comprised $89.5 \%$ of the TC group. Whereas the prevalence of hypertension was comparable in both the groups $(63.2 \%$ in the TC group and $68.3 \%$ in the control group), DM prevalence was significantly lower in those with TC $(12.6 \%$ in the TC group and $29.7 \%$ in the control group).

\section{Meta-analysis}

In a meta-analysis of 959 papers including 794 single or multiple patient case reports and 165 case series, comprising a total of 33,894 TC patients, the prevalence of DM and hypertension was evaluated. ${ }^{[5]}$ The identification of the prevalence of DM was the primary purpose of this analysis, with the prevalence of hypertension used as an index of representativeness of the TC patients to the general population. Five sub-analysis were performed in this study. In the first analysis, which included all TC patients including single case reports and small and large case series, comprising 33,894 patients (mean age 67.3 years and $89 \%$ females), $57.4 \%$ had hypertension, while the prevalence of DM was only $16.8 \%$. In the second analysis (included only data from single patient case reports or patient series with patient data reported individually), comprising 1,085 patients (mean age 61.7 years and $86.3 \%$ females), $42.8 \%$ had hypertension and only $10.2 \%$ had DM. In the third analysis, using patient case series with patient data reported collectively and excluding individually reported patients and comprising 32,809 patients (mean age 67.3 years, $89 \%$ females), $57.9 \%$ had hypertension while the prevalence of DM was $17 \%$. In the fourth analysis (TC patients aged $>60$ years, from case reports and case series with patient data reported individually) of 687 patients (mean age 72.2 years and $89 \%$ females), $50.4 \%$ had hypertension while the prevalence of DM was $11.9 \%$. Finally, in the fifth analysis (TC patients > 65 years from singe patient case reports and case series in which data on patients were reported individually), comprising 550 TC patients (mean age 74.6 years and $91.1 \%$ females), $52.2 \%$ had hypertension while only $12.5 \%$ had DM. All five analyses in this study thus consistently indicated a high prevalence of hypertension (> 50\%), similar to the global and US rates of hypertension prevalence (prevalence of age adjusted hypertension was $65.4 \%$ for those $>60$ years in the National Health and Nutrition Evaluation Survey or NHANES study and $60-65 \%$ globally). Given that hypertension prevalence was used an index of representativeness of the TC patients to the general population in this meta-analysis, it was assumed that the TC patient population was a comparable representative of the general population. Conversely, in all 5 analyses, DM had a low prevalence, with prevalence rates of $16.8 \%, 10.2 \%, 17 \%, 11.9 \%$ and $12.5 \%$, respectively. These prevalence rates were significantly lower than prevalence rates of DM in similar age matched populations. Furthermore, this study was a global analysis, using TC patients from the entire world literature of TC. Global estimates of DM prevalence in the elderly is around $20 \%$, and in this study, was $11.9 \%$ and $12.5 \%$ in the individual case analyses of patients over 60 and 65 years of age, respectively. Thus, the prevalence of DM in the TC patients was approximately half the expected prevalence rate of DM. In addition, in an analysis of 14 case series, with each case series comprising over 
100 TC patients, the prevalence of DM ranged from $1.6 \%$ to $25.5 \%$. The prevalence of DM in 9 out of the 14 patient series was $<16 \%$, lower than the rates in the US and the global population. In addition, the prevalence of DM in 5 of the 14 patient series was $<9 \%$, which is only one third the prevalence of DM in the general population over 65 years of age. The prevalence of hypertension ranged from $27.0 \%$ to $73.0 \%$, and was over $50 \%$ in 10 of the 14 series, which is similar to the rates of hypertension prevalence in the US and the global population. In conclusion, results of all sub-analyses of the study demonstrated a compelling evidence to suggest a much lower prevalence of DM in TC and are suggestive of a potential protective effect of DM in the development of TC [Table 1].

\section{DISCUSSION}

This data raises a possibility that sympathetic blockade and sympathectomy may be effective in preventing stress related cardiac dysfunction. ${ }^{[26,27]}$ The protective effect of DM in TC may be secondary to autonomic neuropathy and/or hypo secretion of catecholamines in diabetic patients. ${ }^{[26-30]}$ Diabetic neuropathy can affect up to $50 \%$ of patients with both type- 1 and type-2 DM, with reduction of counter regulatory catecholamine secretion. ${ }^{[5]}$ The pathogenesis of TC is thought to involve an autonomic or catecholamine storm, with primarily locally released catecholamines and blood borne systemic catecholamines. Since cardiac autonomic innervation is extensive, the catecholamine toxicity results in neurocardiac deleterious effects and myocardial stunning. Autonomic neuropathic changes in diabetics result in neuropathic changes in splanchnic autonomic sympathetic nerves or in adrenal chromaffin cells which are innervated by these autonomic nerves, and result in hyposecretion of epinephrine by the adrenals. Diabetic patients may also have autonomic neuropathy of cardiac sympathetic nerves. Clinical studies have documented reduced norepinephrine release in cardiac tissue in patients with type-2 DM and this has also been seen in rat models. ${ }^{[5]}$ Thus, DM may serve as a protective factor in the development of TC with blunting of cardiac and splanchnic autonomic nervous system effects, with reduced local cardiac norepinephrine release and reduced systemic epinephrine release [Figure 1]. ${ }^{[28,29]}$ Animal studies showing the beneficial effects of sympathetic blockade on prevention of development of TC may further support the sympathetic/catecholamine surge model of pathogenesis of TC. ${ }^{[31]}$

One may thus speculate that diabetic patients with more severe disease or prolonged disease duration may be comparatively more immune towards the
Table 1: Diabetes mellitus prevalence in studies of takotsubo cardiomyopathy patients

\begin{tabular}{|c|c|c|c|}
\hline Authors & $\begin{array}{l}\text { No. of } \\
\text { patients }\end{array}$ & $\begin{array}{l}\text { Age (years), mean } \\
\pm \text { SD or range, } \\
\text { ( } \% \text { of female) }\end{array}$ & $\begin{array}{c}\text { DM } \\
\text { prevalence } \\
(\%)\end{array}$ \\
\hline Pelliccia et al. ${ }^{[8]^{*}}$ & 1,109 & $59-76(86)$ & $17^{*}$ \\
\hline Núñez-Gil et al. ${ }^{[9]}$ & 328 & $69.7 \pm 12.6(90.2)$ & 13.1 \\
\hline Khalid et al. ${ }^{[11]}$ & 16 & $68.3 \pm 10.9(100)$ & 6.25 \\
\hline Brinjikji et al..$^{[12]}$ & 24,701 & $66.9 \pm 30.7(89.0)$ & 18.9 \\
\hline Patel et al..$^{[13]}$ & 224 & $71.7 \pm 10.4(94.6)$ & 13.8 \\
\hline Dias et al. ${ }^{[14]}$ & 206 & $67.8(87)$ & 19.0 \\
\hline Auzal et al. ${ }^{[15]}$ & 90 & $71.9 \pm 12.7(97)$ & 9.0 \\
\hline Khera et al. ${ }^{[16]}$ & 22,005 & $65.7(92.0)$ & $18.0^{\wedge}, 2.6^{\circ}$ \\
\hline Eitel et al. ${ }^{[17]}$ & 256 & $69 \pm 12(89)$ & 19.0 \\
\hline Núñez-Gil et al. ${ }^{[18]}$ & 100 & $68(89)$ & 18.0 \\
\hline Núñez-Gil et al. ${ }^{[19]}$ & 202 & $70 \pm 12.5(90.1)$ & 15.3 \\
\hline Templin et al..$^{[20]}$ & 1750 & $66.4 \pm 13.1(89.8)$ & 14.2 \\
\hline Citro et al. ${ }^{[22]}$ & 190 & $66 \pm 11.4(92)$ & 5.7 \\
\hline Falola et al. ${ }^{[23]}$ & 1,724 & $65.3(90.2)$ & 1.6 \\
\hline Tornvall et al..$^{[24]}$ & 505 & $67 \pm 10(87.5)$ & 6.5 \\
\hline $\begin{array}{l}\text { Zalewska-Adamiec } \\
\text { et al. }{ }^{[25]}\end{array}$ & 101 & $67.6 \pm 4.2(89.5)$ & 12.6 \\
\hline \multicolumn{4}{|l|}{ Madias $^{[5]} \dagger$} \\
\hline Analysis 1 & 33,894 & $67.3 \pm 6.0(88.9)$ & 16.8 \\
\hline Analysis 2 & 1,085 & $61.7 \pm 16.7(86.3)$ & 10.2 \\
\hline Analysis 3 & 32,809 & $67.3 \pm 6.0(89.0)$ & 17.0 \\
\hline Analysis 4 & 687 & $72.2 \pm 7.7(89.5)$ & 11.9 \\
\hline Analysis 5 & 550 & $74.6 \pm 6.6(91.1)$ & 12.5 \\
\hline Sara et al. ${ }^{[33]}$ & 1,439 & $51.1(65.1)$ & 8.8 \\
\hline
\end{tabular}

*Systematic review including 19 studies; †analysis 1 - all patients included in meta-analysis, analysis 2 - individual patient cases, analysis 3 - patient case series, analysis 4 - individual patient cases $>60$ years, analysis 5 - individual patient cases $>65$ years; ^prevalence of uncomplicated diabetes; ${ }^{\circ}$ prevalence of complicated diabetes. DM: diabetes mellitus

development of TC. ${ }^{[10,29,30]}$ However, almost certainly, an interplay of factors such as DM, magnitude of the stressful stimulus (physical and emotional), presence and severity of the associated comorbid conditions and illnesses, would collaboratively play a role in the pathogenesis of TC. Thus, severe stressful triggers, physical and emotional and/or severe illness such as sepsis could still precipitate TC even in patients with severe or prolonged DM. This is supported by the fact that cases of development of TC have been previously reported in diabetic patients with severe sepsis and those with situations of overwhelming stress such as diabetic ketoacidosis, ${ }^{[32]}$ suggesting that these conditions may overpower the protective effect of DM.

Coronary microvascular dysfunction is another mechanism which has been increasingly recognized as a significant factor in the pathogenesis of TC. ${ }^{[4,6,7]}$ The importance of coronary microvascular dysfunction is also well established in Syndrome X. In a recent study of 1,439 patients (mean age 51 years, $65.1 \%$ women) with chest pain and non-obstructive CAD on coronary angiography, the presence of microvascular dysfunction was assessed. ${ }^{[33]}$ Intracoronary Doppler 


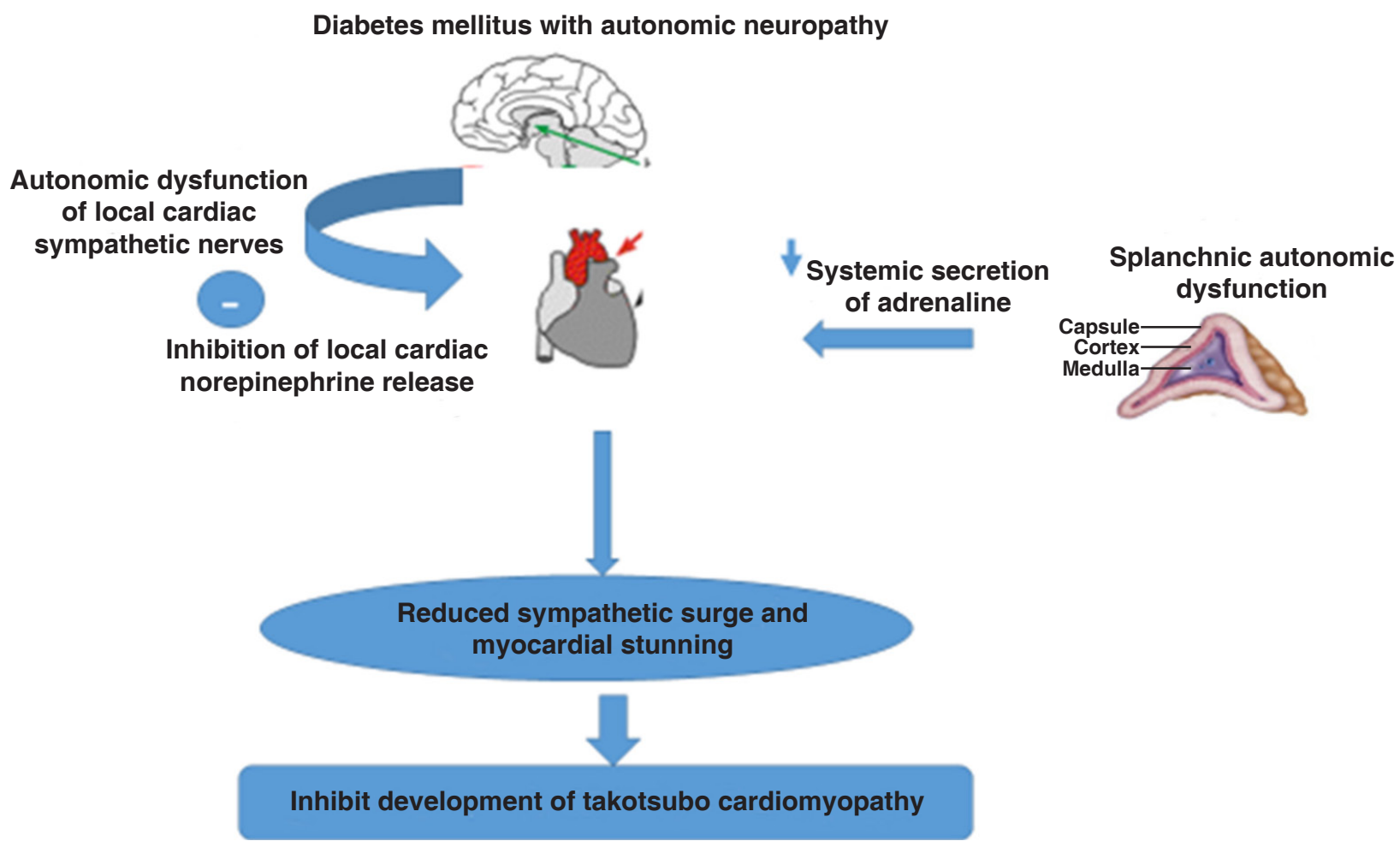

Figure 1: Pathophysiologic mechanism of protective effect of diabetes mellitus on development of takotsubo cardiomyopathy

measurements of hemodynamics in response to acetylcholine and adenosine were used for evaluation. Microvascular dysfunction was noted to be present in a large proportion of patients (64\%). Evaluation of underlying cardiac risk factors showed that hyperlipidemia and hypertension were common, with hyperlipidemia seen in up to $61 \%$ and hypertension in up to $46 \%$ of patients. A noteworthy finding was that DM was quite uncommon in all patient groups, with the prevalence of DM only ranging from $7 \%$ to $12 \%$. Since microvascular dysfunction has been increasingly thought to be one of the pivotal factors in the pathogenesis of TC, it somewhat supports an interesting association since diabetics also have a lower incidence of TC. ${ }^{[31]}$ On the contrary, some studies have also suggested increasing prevalence of coronary microvascular dysfunction in diabetics. ${ }^{[31,34,35]}$ Given that microvascular dysfunction is also an important pathogenic factor in TC, this discordance currently has no clear explanation and needs further evaluation. Future studies will strengthen our understanding on this subject.

\section{CONCLUSION}

Knowledge about the pathogenesis and risk factors associated with TC is significantly accelerating. Multiple studies have reported low prevalence and rates of DM in patients with TC. This is lower than the prevalence rates of diabetes in the general population, and in contrast to higher prevalence rates of DM in ACS patients. DM may confer a protective effect on the evolution of TC. An increasingly plausible explanation is that autonomic neuropathy from DM leads to cardiac sympathetic autonomic dysfunction and splanchnic autonomic dysfunction resulting in reduced local norepinephrine release and reduced systemic epinephrine release from chromaffin cells in the adrenal medulla, respectively. This autonomic neuropathy and catecholamine hyposecretion may lead to significant blunting and amelioration of cardiomyocyte injury and myocardial stunning, resulting from the catecholamine storm/surge thought to occur in the pathogenesis of TC. Further retrospective and prospective studies on TC should ensure accurate reporting of the underlying prevalence of comorbid conditions, including characterizing the particulars of diabetes mellitus in this population, to further define the postulated protective role of diabetes in these patients.

\section{LIMITATIONS AND FUTURE DIRECTIONS}

The data currently available on the subject is quite limited. The prevalence of DM in most of the studies remains relatively low. Dedicated studies on TC are needed incorporating patients with DM to explore the relationship further between DM and TC. Since the studies currently available are mainly retrospective and case-control studies, further prospective studies are needed to strengthen our understanding of 
the pathophysiological basis of TC. It would be extremely informative if future case series, case reports and $\mathrm{TC}$ registries maintain and report more detailed information about the diabetes status of TC patients. Details like type of DM, chronicity, use of oral hypoglycemic agents, use of insulin, $\mathrm{HbA1c}$ values, uncomplicated, complicated by dysautonomia, chronic kidney disease, microvascular disease and presence of end organ damage need to be collected to further study the association between TC and DM. Future studies also need to highlight the presence of other comorbities like hypertension, dyslipidemia and coronary microvascular dysfunction and their interaction with diabetes to better elucidate the effect of DM in the pathogenesis of TC.

\section{DECLARATIONS}

\section{Authors' contributions}

Did literature review and composed the first draft of the article: S. Gowdar

Reviewed data and worked on the subsequent revisions: S. Syal

Conceptualized the study design, reviewed progress of the article at each step, and finalized the manuscript of the review article: L. Chhabra

\section{Financial support and sponsorship \\ None.}

\section{Conflicts of interest}

There are no conflicts of interest.

\section{Patient consent}

Not applicable.

\section{Ethics approval}

Not applicable.

\section{REFERENCES}

1. Parodi G, Del Pace S, Carrabba N, Salvadori C, Memisha G, Simonetti I, Antoniucci D, Gensini GF. Incidence, clinical findings, and outcome of women with left ventricular apical ballooning syndrome. $\mathrm{Am} \mathrm{J}$ Cardiol 2007;99:182-5.

2. Akashi YJ, Goldstein DS, Barbaro G, Ueyama T. Takotsubo cardiomyopathy: a new form of acute, reversible heart failure. Circulation 2008;118:2754-62.

3. Sato H, Tateishi H, Uchida T. Takotsubo-type cardiomyopathy due to multivessel spasm. In: Kodama K, Haze K, Hon M, editors. Clinical Aspect of Myocardial Injury: From Ischemia to Heart Failure. Tokyo, Japan: Kagakuhyouronsha; 1990. p. 56-64.

4. Gowdar S, Chhabra L. Microvascular dysfunction in takotsubo cardiomyopathy. ICF J 2016;5:40-9.

5. Madias JE. Low prevalence of diabetes mellitus in patients with Takotsubo syndrome: a plausible 'protective' effect with pathophysiologic connotations. Eur Heart J Acute Cardiovasc Care 2016;5:164-70.

6. Khalid N, Chhabra L. Takotsubo cardiomyopathy and microcirculatory dysfunction. Nat Rev Cardiol 2015;12:497.

7. Khalid N, Ahmad SA, Umer A. Coronary flow reserve assessment via invasive and noninvasive means in Takotsubo cardiomyopathy. Int $J$ Cardiol 2016;202:573.

8. Pelliccia F, Parodi G, Greco C, Antoniucci D, Brenner R, Bossone E, Cacciotti L, Capucci A, Citro R, Delmas C, Guerra F, Ionescu CN, Lairez O, Larrauri-Reyes M, Lee PH, Mansencal N, Marazzi G, Mihos CG, Morel O, Nef HM, Nunez Gil IJ, Passaseo I, Pineda AM, Rosano G, Santana O, Schneck F, Song BG, Song JK, Teh AW, Ungprasert P, Valbusa A, Wahl A, Yoshida T, Gaudio C, Kaski JC. Comorbidities frequency in Takotsubo syndrome: an international collaborative systematic review including 1109 patients. Am J Med 2015;128:654.e11-9.

9. Núñez-Gil IJ, Almendro-Delia M, Andrés M, Sionis A, Martin A, Bastante T, Córdoba-Soriano JG, Linares JA, González Sucarrats S, Sánchez-Grande-Flecha A, Fabregat-Andrés O, Pérez B, EscudierVilla JM, Martin-Reyes R, Pérez-Castellanos A, Rueda Sobella F, Cambeiro C, Piqueras-Flores J, Vidal-Perez R, Bodí V, García de la Villa B, Corbí-Pascua M, Biagioni C, Mejía-Rentería HD, Feltes G, Barrabés J; RETAKO investigators. Secondary forms of Takotsubo cardiomyopathy: a whole different prognosis. Eur Heart $J$ Acute Cardiovasc Care 2016;5:308-16.

10. Madias JE. Diabetes mellitus and Takotsubo syndrome in two Spanish cohorts. Eur Heart J Acute Cardiovasc Care 2016;5:297.

11. Khalid N, Iqbal I, Coram R, Raza T, Fahsah I, Ikram S. Thrombolysis in myocardial infarction frame count in takotsubo cardiomyopathy. Int J Cardiol 2015;191:107-8.

12. Brinjikji W, El-Sayed AM, Salka S. In-hospital mortality among patients with takotsubo cardiomyopathy: a study of the National Inpatient Sample 2008 to 2009. Am Heart J 2012;164:215-21.

13. Patel SM, Chokka RG, Prasad K, Prasad A. Distinctive clinical characteristics according to age and gender in apical ballooning syndrome (takotsubo/stress cardiomyopathy): an analysis focusing on men and young women. $J$ Card Fail 2013;19:306-10.

14. Dias A, Franco E, Rubio M, Koshkelashvili N, Bhalla V, Amanullah S, Hebert K, Figueredo VM. Takotsubo syndrome: does it matter if you have diabetes mellitus? Int J Cardiol 2016;224:398-9.

15. Auzel O, Mustafic H, Pillière R, El Mahmoud R, Dubourg O, Mansencal N. Incidence, characteristics, risk factors, and outcomes of takotsubo cardiomyopathy with and without ventricular arrhythmia. Am J Cardiol 2016;117:1242-7.

16. Khera R, Light-McGroary K, Zahr F, Horwitz PA, Girotra S. Trends in hospitalization for takotsubo cardiomyopathy in the United States. Am Heart J 2016;172:53-63.

17. Eitel I, von Knobelsdorff-Brenkenhoff F, Bernhardt P, Carbone I, Muellerleile K, Aldrovandi A, Francone M, Desch S, Gutberlet M, Strohm O, Schuler G, Schulz-Menger J, Thiele H, Friedrich MG. Clinical characteristics and cardiovascular magnetic resonance findings in stress (takotsubo) cardiomyopathy. JAMA 2011;306:27786.

18. Núñez-Gil IJ, Molina M, Bernardo E, Ibañez B, Ruiz-Mateos B, García-Rubira JC, Vivas D, Feltes G, Luaces M, Alonso J, Zamorano J, Macaya C, Fernández-Ortiz A. Tako-tsubo syndrome and heart failure: long-term follow-up. Rev Esp Cardiol (Engl Ed) 2012;65:9961002.

19. Núñez Gil IJ, Andrés M, Almendro Delia M, Sionis A, Martín A, Bastante T, Córdoba Soriano JG, Linares Vicente JA, González Sucarrats S, Sánchez-Grande Flecha A; RETAKO investigators. Characterization of Tako-tsubo cardiomyopathy in Spain: results from the RETAKO National Registry. Rev Esp Cardiol (Engl Ed) 
2015;68:505-12.

20. Templin C, Ghadri JR, Diekmann J, Napp LC, Bataiosu DR, Jaguszewski M, Cammann VL, Sarcon A, Geyer V, Neumann CA, Seifert B, Hellermann J, Schwyzer M, Eisenhardt K, Jenewein J, Franke J, Katus HA, Burgdorf C, Schunkert H, Moeller C, Thiele H, Bauersachs J, Tschöpe C, Schultheiss HP, Laney CA, Rajan L, Michels G, Pfister R, Ukena C, Böhm M, Erbel R, Cuneo A, Kuck KH, Jacobshagen C, Hasenfuss G, Karakas M, Koenig W, Rottbauer W, Said SM, Braun-Dullaeus RC, Cuculi F, Banning A, Fischer TA, Vasankari T, Airaksinen KE, Fijalkowski M, Rynkiewicz A, Pawlak M, Opolski G, Dworakowski R, MacCarthy P, Kaiser C, Osswald S, Galiuto L, Crea F, Dichtl W, Franz WM, Empen K, Felix SB, Delmas C, Lairez O, Erne P, Bax JJ, Ford I, Ruschitzka F, Prasad A, Lüscher TF. Clinical features and outcomes of takotsubo (stress) cardiomyopathy. N Engl J Med 2015;373:929-38.

21. Madias JE. Baroreceptor dysfunction, diabetes mellitus, and takotsubo syndrome: an intricate triangle needing exploration. Int $J$ Cardiol 2015;184:517-8

22. Citro R, Rigo F, Previtali M, Ciampi Q, Canterin FA, Provenza G, Giudice R, Patella MM, Vriz O, Mehta R, Baldi C, Mehta RH, Bossone E. Differences in clinical features and in-hospital outcomes of older adults with tako-tsubo cardiomyopathy. J Am Geriatr Soc 2012;60:93-8.

23. Falola M, Fonbah W, McGwin G Jr. Takotsubo cardiomyopathy versus ST-elevation myocardial infarction in a large case-control study: proposing a new mechanism. Int J Cardiol 2013;167:1079-81.

24. Tornvall P, Collste O, Ehrenborg E, Järnbert-Petterson H. A casecontrol study of risk markers and mortality in takotsubo stress cardiomyopathy. J Am Coll Cardiol 2016;67:1931-6.

25. Zalewska-Adamiec M, Bachorzewska-Gajewska H, TomaszukKazberuk A, Nowak K, Drozdowski P, Bychowski J, Krynicki R, Musial WJ, Dobrzycki S. Takotsubo cardiomyopathy: serious early complications and two-year mortality - a 101 case study. Neth Heart J 2016;24:511-19

26. Boland TA, Lee VH, Bleck TP. Stress-induced cardiomyopathy. Crit Care Med 2015;43:686-93.

27. Khalid N, Ahmad SA, Umer A, Chhabra L. Role of microcirculatory disturbances and diabetic autonomic neuropathy in takotsubo cardiomyopathy. Crit Care Med 2015;43:e527.

28. Khalid N, Chhabra L, Ahmad SA, Sareen P, Spodick DH. Autonomic dysfunction and takotsubo cardiomyopathy. Am JMed 2015;128:e45-6

29. Chhabra L. Brain-heart disconnection: a protective effect of diabetes mellitus in takotsubo cardiomyopathy. Am J Cardiol 2016;117:1858.

30. Chhabra L, Sareen P. Takotsubo cardiomyopathy and microvascular dysfunction. Int J Cardiol 2015;196:107.

31. Chhabra L, Kowlgi NG. Low incidence of diabetes mellitus in coronary microvascular dysfunction: an intriguing association. JACC Cardiovasc Interv 2016;9:395-6.

32. Ohigashi-Suzuki S, Saito Y, Tatsuno I. Takotsubo cardiomyopathy associated with sepsis in type 2 diabetes mellitus. Am J Emerg Med 2007;25:230-2.

33. Sara JD, Widmer RJ, Matsuzawa Y, Lennon RJ, Lerman LO, Lerman A. Prevalence of coronary microvascular dysfunction among patients with chest pain and nonobstructive coronary artery disease. JACC Cardiovasc Interv 2015;8:1445-53.

34. Kawata T, Daimon M, Miyazaki S, Ichikawa R, Maruyama M, Chiang SJ, Ito C, Sato F, Watada H, Daida H. Coronary microvascular function is independently associated with left ventricular filling pressure in patients with type 2 diabetes mellitus. Cardiovasc Diabetol 2015;14:98.

35. Sucato V, Evola S, Quagliana A, Novo G, Andolina G, Assennato P, Novo S. Comparison of coronary artery flow impairment in diabetic and hypertensive patients with stable microvascular angina. Eur Rev Med Pharmacol Sci 2014;18:3687-9. 